BIS

WORKING PAPERS No. 46

\title{
GLOBAL ASSET ALLOCATION IN FIXED INCOME MARKETS
}

\author{
by \\ Srichander Ramaswamy
}

September 1997

BANK FOR INTERNATIONAL SETTLEMENTS

Monetary and Economic Department

BASLE 
BIS Working Papers are written by members of the Monetary and Economic Department of the Bank for International Settlements, and from time to time by other economists, and are published by the Bank. The papers are on subjects of topical interest and are technical in character. The views expressed in them are those of their authors and not necessarily the views of the BIS.

(C) Bank for International Settlements 1997

CH-4002 Basle, Switzerland

Also available on the BIS World Wide Web site (http://www.bis.org).

All rights reserved. Brief excerpts may be reproduced or translated provided the source is stated.

ISSN 1020-0959 


\title{
GLOBAL ASSET ALLOCATION IN FIXED INCOME MARKETS *
}

\author{
by \\ Srichander Ramaswamy
}

September 1997

\begin{abstract}
Many global investors are faced with the problem of choosing an appropriate currency allocation of their assets in the capital markets. This paper addresses the asset allocation problem under the assumption that the investment universe is comprised of unhedged risk-free bonds in different countries. In general, the total return arising from holding an unhedged bond portfolio is comprised of two components. One component of the return arises from the bond price changes resulting from yield curve movements and the other component arises from exchange rate fluctuations. In this paper, bond price changes are assumed to be governed by a one factor interest rate term structure model. The return arising from exchange rate changes is extracted by modelling the evolution of exchange rates as a jump stochastic process. The jump process is assumed to occur in the volatility of exchange rate returns. This model is consistent with the empirical evidence that the volatility of currency returns exhibits GARCH behaviour. Using the models that describe the evolution of interest rates and exchange rates, the optimal portfolio allocation problem is solved in a mean-variance setting by Monte Carlo simulation. The out-of-sample performance of the portfolios selected is also presented and is compared against those obtained using other existing methods.
\end{abstract}

\footnotetext{
The author is a Fixed Income Analyst in the Banking Department of the BIS. He would like to thank in particular Greg Sutton and Konstantinos Tsatsaronis whose careful reading and critical comments considerably improved the quality of this paper. Stephan Arthur's professional skills during proof-reading and publishing made a difficult job look easy. Helpful comments from Jean-Pierre Matt, Ludwig Chincarini, Pierre Cardon and Jean-Francois Rigaudy are also appreciated.
} 



\section{Contents}

Introduction

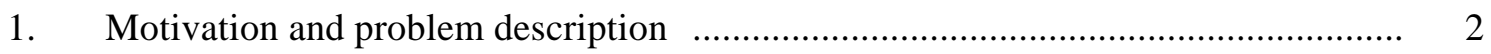

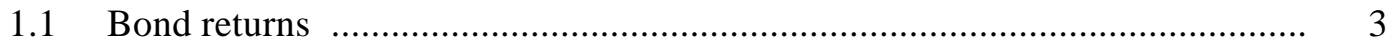

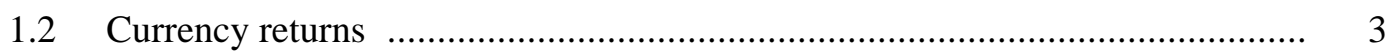

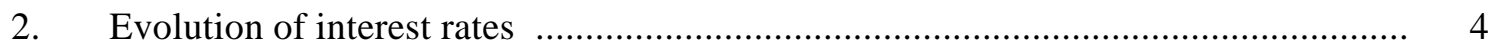

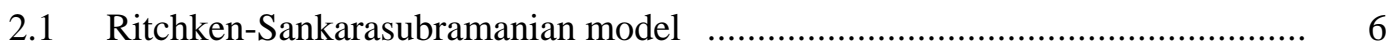

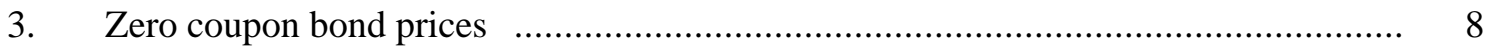

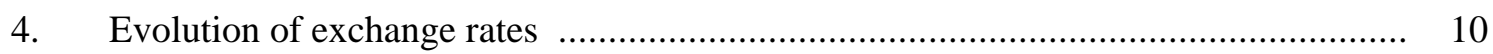

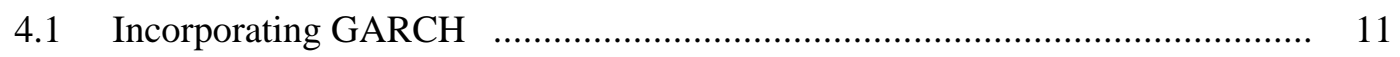

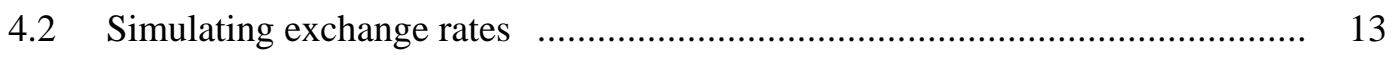

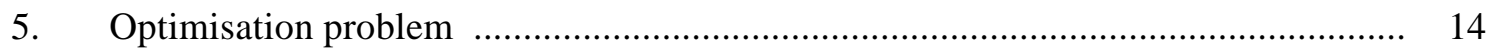

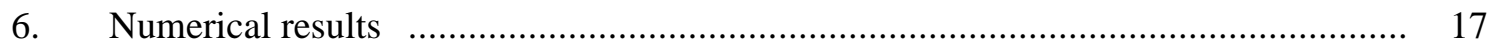

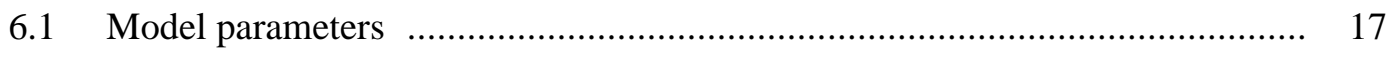

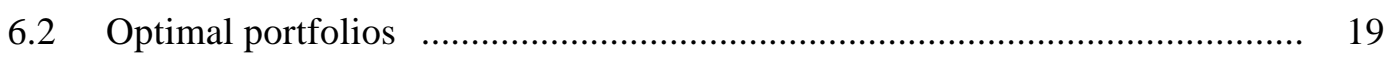

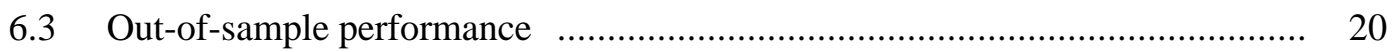

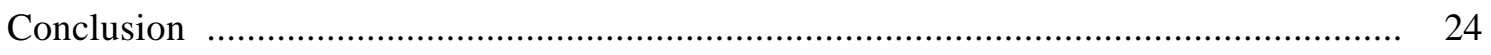

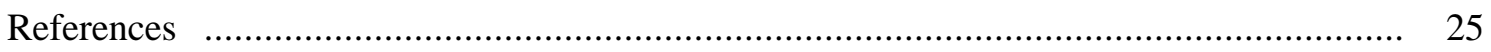





\section{Introduction}

A general problem faced by institutional investors is to choose a portfolio that maximises expected return for a given level of risk. It will be assumed in the present study that the permissible asset class in which investments can be made consists of global fixed income securities. The goal of the present study is to find the optimum allocation of available funds in various fixed-income securities on an unhedged currency basis such that, over a specified time horizon and for a given level of risk, the expected return measured in the base currency is maximised.

The asset allocation problem being addressed here has been extensively studied in the literature (see Black and Litterman (1992), Dumas and Jacquillat (1990), Hann (1995) and Lederman and Klein (1994)). Many of these studies address the problem of global asset allocation through the use of quantitative models. The most common among them are CAPM type models where the investor's preference function is expressed as a trade-off between expected return and risk. ${ }^{1}$ Yet asset allocation strategies driven by quantitative models have not played an important role in global portfolio allocation. One well-known problem with the mean-variance optimisation framework is that under the constraint of no short sales the model picks unreasonably large weights in markets with small capitalisation and zero weights in many other markets. Further, the out-of-sample performance (measured in terms of realised return and volatility of returns) of tangent portfolios selected by solving a mean-variance optimisation problem has been less than satisfactory.

The primary reason for the unsatisfactory out-of-sample performance of tangent portfolios lies in the nature of inputs supplied to find an optimal portfolio. In most cases, the information concerning expected returns is estimated using historical data and the composition of the optimal portfolio tends to be quite sensitive to the period of historical data used. Most studies reported in the literature propose alternative ways of addressing this estimation error problem. For instance, Jorion (1985) develops a Bayesian solution known as Bayes-Stein shrinkage estimator. This involves forming expectations partly on historical data and partly on the prior that all expected returns are equal but unknown. Such an assumption results in the optimal portfolio being close to the minimumvariance portfolio. Dumas and Jacquillat (1990), on the other hand, propose a neutral prior that assigns equal weights to all assets. The method proposed by Black and Litterman (1992) assumes the existence of an equilibrium risk premium which is defined as the excess return that equates the supply and demand for global assets and currencies. This equilibrium risk premium is used to provide a neutral benchmark. Expressing views that differ from this benchmark allows investors to form optimal portfolios that deviate from the equilibrium framework.

1 Other types of models that use asymmetric risk measures have also been reported in the literature although these tend to be less popular in the investment industry (see King (1993) and Markowitz et al. (1993)). 
The present paper addresses the issue of asset allocation in global fixed income markets. The main contribution of this paper is the methodology used to compute the distribution of expected returns on an unhedged global bond portfolio. This is done by using stochastic models that describe the evolution of interest rates and exchange rates and carrying out Monte Carlo simulations to compute the distribution of expected returns over the investment horizon. Also new in the present study is the model used to describe the evolution of exchange rates. An important element of this model is that it allows for random jumps in the volatility function and therefore incorporates the empirically observed GARCH phenomenon in the volatility of exchange rates (see Engle and Bollerslev (1996), Xu and Taylor (1994) and Heynen et al. (1994)). Using the first two moments of the return distribution computed from the Monte Carlo study, optimal portfolios are determined by solving a mean-variance optimisation problem.

The rest of the paper is organised as follows. Section 1 considers the problem description and provides the motivation for the present study. Section 2 describes the modelling of short-term interest rates. Section 3 outlines how zero coupon bond prices can be simulated by using the shortterm interest rate model described in Section 2. The modelling of the exchange rate process and a numerical scheme to simulate sample paths of exchange rates is described in detail in Section 4. The optimisation problem for selecting the desirable global bond portfolio is formulated in Section 5. Numerical results are presented in Section 6. The final section concludes.

\section{Motivation and problem description}

This section gives a brief description of the methodology used in the present study to find optimal portfolios and helps to provide motivation for the problem being addressed in this paper. As pointed out in the introduction, different studies of optimal portfolio choice use different methods to compute expected returns and the out-of-sample performance of the portfolio chosen depends crucially on this forecast. Most studies address the problem of how to estimate the future expected return with minimum estimation error. This paper addresses the global asset allocation problem under the assumption that the foreign currency portfolio is comprised of unhedged bonds in different countries. The total return arising from holding an unhedged bond portfolio is comprised of two components. One component of the return arises from the bond price changes resulting from yield curve movements and the other component arises from exchange rate changes. The main contribution of this paper is the methodology used to model the distribution of the total return obtained on holding an unhedged bond portfolio. This is done by modelling the evolution of zero coupon bond prices and exchange rates individually in order to compute the distribution of the total return from holding the bond portfolio. A brief description of the way this is done is given below. 


\subsection{Bond returns}

The price of a bond depends on the current structure of interest rates. This being the case, the return obtained from holding a bond portfolio over a given investment horizon depends on the evolution of the entire term structure of interest rates. In general, for short-term horizons (one to three months), expected yield changes of coupon bonds can provide a useful forecast on the expected returns when holding a bond portfolio. However, when the investment horizon is medium term (one year or longer), such yield forecasts are less reliable for computing the expected return. Moreover, the use of historical returns may be inappropriate for the reason that either the yield levels or economic factors that determine the term structure of interest rates might have changed. Since, at any given time the term structure of interest rates contains complete information concerning expected future returns, the use of this information is considered to be most appropriate when it comes to modelling bond returns. Hence, in order to be able to model the distribution of returns from holding a bond portfolio over the medium term, one needs to model the evolution of the term structure of interest rates. The present study models the evolution of zero coupon bond prices by using a term structure interest rate model in order to compute the distribution of bond returns over the given investment horizon. The choice of a suitable term structure model is described in Section 2 and the simulation of zero coupon bond prices, which in turn is used to model the return distribution over the investment horizon, is discussed in Section 3.

\subsection{Currency returns}

The other component of the return on holding an unhedged bond portfolio comes from exchange rate fluctuations. The evolution of the exchange rate between any two currencies is a function of many factors including the interest rate differential between the countries. However, in practice, the exchange rate changes over a given time interval can vary significantly from the one predicted by the interest rate differential between the countries. Moreover, the volatility of exchange rate returns over certain time periods are considerably higher than the historical average. Incorporating such a behaviour in the model that describes the evolution of exchange rates will provide a more realistic description of the distribution of returns resulting from currency changes when holding an unhedged bond portfolio. Section 4 describes such an exchange rate model where the volatility of exchange rates is assumed to undergo random jumps and then decays to the historical average level. This behaviour is modelled by use of a Poisson jump process in the volatility function of the exchange rates. Such a model allows for GARCH behaviour in the exchange rates. The drift term of the exchange rate model is assumed to be the short-term interest rate differential between the countries.

Using the models that describe the evolution of zero coupon bond prices and exchange rates, Monte Carlo simulation is carried out to compute the distribution of returns in the base currency when holding an unhedged bond portfolio. The first two moments of the return distribution are then 
used to compute optimal portfolios by formulating a mean-variance optimisation problem. The details are given in Section 5.

\section{Evolution of interest rates}

In this section, the choice of a suitable model to describe the evolution of short-term interest rates is discussed. This is required in order to be able to compute the distribution of bond returns over the investment horizon. In general, the price of any interest rate contingent claim is dependent on the term structure of interest rates and its stochastic evolution. In the selection of interest rate models to value such securities, one is confronted with many alternative choices. Some of the important interest rate models proposed in the literature are examined in the paper by Rogers (1993), the most popular of which is the one factor interest rate model. The reason for this model's popularity is that about $70-75 \%$ of the term structure variance can be accounted for by a single factor and it leads to a tractable model for valuing claims on interest rate sensitive securities. The underlying assumption in the one factor models is that bond prices are driven by the short-term rate, which has a mean reverting property. However, the most general interest rate model is the multi-factor model proposed by Heath, Jarrow and Morton (1992) (HJM). In this model the evolution of the forward rates are modelled and it requires the volatilities of all instantaneous forward rates at all future times to be specified. The major difficulty with the HJM model is that the resulting instantaneous forward rate process is non-Markovian, and hence, the use of this model will involve excessive computational overheads for valuing contingent claims.

To overcome the difficulty mentioned above, Ritchken and Sankarasubramanian (1995) (RS) apply certain restrictions on the class of allowable volatility functions for the forward rates to obtain a more tractable subset of HJM model. The model considered by RS, which is a one-factor two-state Markovian model, is both theoretically well justified and feasible to implement. The RS model is more general than the Cox, Ingersoll and Ross (CIR) model (see Cox, Ingersoll and Ross (1985)), and further, unlike the CIR model which is an equilibrium model, the RS model is a no arbitrage interest rate model. Most recent studies indicate that the RS class of models are more realistic in modelling the term structure of interest rates (see Bliss and Ritchken (1996)), and hence, this model will be used in the present study for simulating prices of zero coupon bonds.

The following notations will be used below to describe the evolution of interest rates and zero coupon bond prices.

$P(t, T): \quad$ Price at time $t$ of a discount bond with principal $\$ 1$ maturing at time $T$

$f(t, T): \quad$ Instantaneous forward rate from time $t$ to $T$

$\sigma_{f}(t, T)$ Volatility of forward interest rate

$y(t, T)$ Continuously compounded yield at time $t$ for a zero-coupon bond maturing at time $T$ 
$r(t): \quad$ Spot rate at time $t$

$z(t): \quad$ Wiener process driving term structure movements

By definition, the continuously compounded yield to maturity of a discount bond is given by

$y(t, T)=-\frac{\log (P(t, T))}{T-t}=\frac{1}{T-t} \int_{t}^{T} f(t, s) d s$

The instantaneous forward rates in terms of the bond price can be expressed as

$f(t, T)=-\frac{\partial}{\partial T} \log (P(t, T))$

From the above equations it follows that

$P(t, T)=\exp \left(-\int_{t}^{T} f(t, s) d s\right)$

Note that if the zero coupon yield curve $\{y(t, T)\}_{T=0}^{\infty}$ is available at time $t=0$, then the price of a zero coupon bond at time $t=0$ is given by

$P(0, T)=e^{-y(0, T) T}$

The most general process to describe the evolution of the forward interest rates, as derived by HJM, is given by

$d f(t, T)=m_{f}(t, T) d t+\sigma_{f}(t, T) d z(t)$

In equation (5), $m_{f}(t, T)$ is the drift of the forward interest rate process and is given by

$m_{f}(t, T)=\sigma_{f}(t, T) \int_{t}^{T} \sigma_{f}(t, \tau) d \tau$

The processes $m_{f}(t, T)$ and $\sigma_{f}(t, T)$ in the above equation are assumed to be adapted to the filtration on the underlying probability space. ${ }^{2}$ As pointed out earlier, the difficulty with the HJM model is that the resulting instantaneous forward rate process is non-Markovian, and hence, leads to excessive computational overheads. It is useful to note that the volatility function $\sigma_{f}(t, T)$ of the instantaneous forward rate can be chosen quite arbitrarily. In fact, its selection completely determines the price of all contingent claims since, for each such choice, the drift term is uniquely determined by equation (6).

2 In simple terms, a stochastic process is said to be adapted if the process is measurable with respect to the sigma algebra generated up to the current time. 


\subsection{Ritchken-Sankarasubramanian model}

In order to obtain a more tractable subset of interest rate models among the class of HJM models, RS identify a class of volatility structures that permit the term structure to be represented by a two-state-variable Markovian model (see Ritchken and Sankarasubramanian (1995a)). Their idea is not to remove the path dependence completely, but rather to capture it by a sufficient statistic. In essence, by choosing a restricted set of volatility functions the bond prices can be represented in terms of the short-term interest rate dynamics and a second statistic that captures the history of the term structure dynamics. The class of volatility functions that allows for this is characterised by

$\sigma_{f}(t, T)=\sigma_{f}(t, t) \eta(t, T)$

$\eta(t, T)=\exp \left(-\int_{t}^{T} \psi(s) d s\right)$

In the above equations, $\sigma_{f}(t, t)$ is the volatility of the spot rate at time $t$ (which could be an adapted process) and $\psi(s)$ is some exogeneously provided deterministic function.

For the volatility term structure of the form (7) the bond prices at time $t$ can be expressed in terms of the bond prices at time $t=0$, the spot rate $r(t)$ and a function $\phi(t)$ which represents the accumulated variance for the forward rate up to time $t$. Specifically,

$P(t, T)=\frac{P(0, T)}{P(0, t)} \exp \left[-\beta(t, T)(r(t)-f(0, t))-0.5 \beta^{2}(t, T) \phi(t)\right]$

where

$\beta(t, T)=\int_{t}^{T} \eta(t, s) d s$

and

$\phi(t)=\int_{0}^{t} \sigma_{f}^{2}(s, t) d s \equiv \int_{0}^{t} \sigma_{f}^{2}(s, s) \eta^{2}(s, t) d s$

The dynamics of the two state variables driving the bond prices are given by

$d r(t)=\mu(r, \phi, t) d t+\sigma_{f}(t, t) d z(t)$

$d \phi(t)=\left(\sigma_{f}^{2}(t, t)-2 \psi(t) \phi(t)\right) d t$

with

$\mu(r, \phi, t)=\psi(t)[f(0, t)-r(t)]+\phi(t)+\frac{\partial}{\partial t} f(0, t)$ 
It is important to note here that the class of volatility structures described by equation (7) is quite large since no explicit restriction, apart from boundedness, is imposed on the structure of the spot rate volatilities $\sigma_{f}(t, t)$. For instance, one could choose the spot rate volatility as

$$
\sigma_{f}(t, t)=\sigma[r(t)]^{\gamma}, \quad \gamma \geq 0
$$

where $\gamma$ is referred to as the elasticity parameter. For the choice $\gamma>0$, the spot rate volatility function $\sigma_{f}(t, t)$ is an adapted process. On the other hand, for the choice $\gamma=0$, the spot rate volatility is a deterministic time function. Interest rate models characterised by the volatility functional form given by equation (14) have been studied extensively. For example, setting $\gamma=0$ gives the Vasicek and Hull-White class of models (see Vasicek (1977) and Hull and White (1994)), setting $\gamma=0.5$ corresponds to a square root model of volatility similar to that of Cox, Ingersoll and Ross (1985) and $\gamma=1$ is similar to the lognormal volatility considered by Dothan (1978).

We note that the volatilities of all forward rates, $\sigma_{f}(t, T)$, are related to the spot rate volatilities through the exogeneously specified parameter set $\{\psi(t) \mid t \geq 0\}$. This set can be made as parsimonious as possible. If we set $\psi(t)=\kappa, \forall t$, we obtain models that capture the notion that distant forward rates are less volatile than near term forward rates. On the other hand, choosing $\psi(t)$ to be negative for small values of $t$ and positive for large values of $t$ leads to a humped volatility structure. In a recent study, Bliss and Ritchken (1996) show evidence for selecting an exponentially decaying volatility structure for the forward rates in the US market. For carrying out the asset allocation study, we will assume that a similar forward rate volatility structure exists for all the markets. This can be done by choosing $\psi(t)=\kappa, \forall t$ (with $\kappa$ being different for each market) and restricting the spot rate to have a volatility functional form given by equation (14). This in turn leads to the functional form for the forward rate volatility as

$$
\sigma_{f}(t, T)=\sigma[r(t)]^{\gamma} e^{-\kappa(T-t)}, \quad \kappa \geq 0, \quad \gamma \geq 0
$$

Given this functional form for the volatility, one obtains

$$
\begin{aligned}
& \beta(t, T)=\frac{1}{\kappa}\left[1-e^{-\kappa(T-t)}\right] \\
& d r(t)=\mu(r, \phi, t) d t+\sigma[r(t)]^{\gamma} d z(t) \\
& d \phi(t)=\left(\sigma^{2}[r(t)]^{2 \gamma}-2 \kappa \phi(t)\right) d t, \quad \phi(0)=0 \\
& \mu(r, \phi, t)=\kappa[f(0, t)-r(t)]+\phi(t)+\frac{\partial}{\partial t} f(0, t)
\end{aligned}
$$

The above equations characterise the evolution of the short-term interest rates for any country. By simulating the sample functions of the short-term interest rate process for any country, the 
price at any time $t \in(0, T]$ of zero coupon bonds can be computed using equation (8) for each sample function of the interest rate process. To keep the computational complexity to a minimum, the present study assumes that short-term interest rate processes are uncorrelated across different countries. In the section below, a numerical scheme to simulate the prices of zero coupon bonds will be discussed.

\section{Zero coupon bond prices}

The implementation of a given trading strategy may require the buying and selling of bonds at different times during the investment period. In order to be able to estimate the trading profits that can be expected from such a trading strategy, it is necessary to be able to compute the zero coupon bond prices at any time $t \in(0, T]$. This section presents a numerical scheme to compute the prices of zero coupon bonds at any time $t$ by simulating the sample functions of the short-term interest rate process. To do this, we need a scheme for numerical integration of Ito stochastic differential equations. To make our arguments concrete, let us consider the following Ito stochastic differential equation:

$$
\begin{aligned}
& d x_{t}=m\left(t, x_{t}\right) d t+\sigma\left(t, x_{t}\right) d x_{t} \\
& x_{t_{0}}=x_{0}
\end{aligned}
$$

The simplest numerical integration scheme for equation (20) is the stochastic analogue of the Euler method. The stochastic Euler scheme is obtained by discretising the interval $t \in\left[t_{0}, t_{n}\right]$ into $n$ parts and computing

$\bar{x}(k+1)=\bar{x}(k)+m\left(t_{k}, \bar{x}(k)\right) h+\sigma\left(t_{k}, \bar{x}(k)\right) \Delta w(k)$

where, $h=t_{k+1}-t_{k}$ and $\Delta w(k)=w(k+1)-w(k)$. The random variables $\Delta w(k)$ are independent and normally distributed with $\Delta w(k) \sim N(0, h)$. It can be shown that the order of convergence of the Euler scheme is $o(h)$, i.e.

$$
E\left(x_{t}-\bar{x}_{t}\right)^{2} \rightarrow 0, \quad \text { as } h \rightarrow 0, \quad t \in\left[t_{0}, t_{n}\right]
$$

The order of convergence of the Euler scheme may be too low for certain applications. In order to achieve a higher order of convergence, the Milshtein scheme (see Milshtein (1974)) can be used. For this scheme the discretised equation is given by

$$
\begin{aligned}
\bar{x}(k+1)= & \bar{x}(k)+\left[m\left(t_{k}, \bar{x}(k)\right)-0.5 \sigma\left(t_{k}, \bar{x}(k)\right) \sigma^{\prime}\left(t_{k}, \bar{x}(k)\right)\right] h \\
& +\sigma\left(t_{k}, \bar{x}(k)\right) \Delta w(k)+0.5 \sigma\left(t_{k}, \bar{x}(k)\right) \sigma^{\prime}\left(t_{k}, \bar{x}(k)\right)[\Delta w(k)]^{2}
\end{aligned}
$$

where 


$$
\sigma^{\prime}(t, x)=\frac{\partial \sigma(t, x)}{\partial x}
$$

It can be shown that the order of convergence for the Milshtein scheme is $o\left(h^{2}\right)$.

In order to simulate the sample functions of the short-term interest rate process, the Milshtein scheme will be used in the present study. Under this scheme, the discretised version of the short-term interest rate process for the $i$ th currency is given by

$$
\begin{aligned}
r_{i}(k+1)=r_{i}(k)+[\mu & \left.\left(r_{i}(k), \phi_{i}(k), t_{k}\right)-0.5 \gamma_{i} \sigma_{i}^{2}\left(r_{i}(k)\right)^{2 \gamma_{i}-1}\right] h \\
& +\sigma_{i}\left(r_{i}(k)\right)^{\gamma_{i}} \Delta w_{k}+0.5 \gamma_{i} \sigma_{i}^{2}\left(r_{i}(k)\right)^{2 \gamma_{i}-1}\left(\Delta w_{k}\right)^{2}
\end{aligned}
$$

The sample functions of the interest rate process can be simulated by setting $\Delta w_{i}(k)=\sqrt{h} \xi_{i}(k)$, where $h=\Delta t$ is the step size and $\xi_{i}(k)$ are independent random variables drawn from a standardised normal distribution. The update equation for the ordinary differential equation (18) for the $i$ th currency (see Ritchken and Sankarasubramanian (1995a)) is given by

$$
\phi_{i}(k+1)=e^{-2 \kappa_{i} h} \phi_{i}(k)+\frac{\sigma_{i}^{2}\left[r_{i}(k)\right]^{2 \gamma_{i}}}{2 \kappa_{i}}\left[1-e^{-2 \kappa_{i} h}\right]
$$

Using equations (16), (25) and (26), the price at any time $t$ of the zero coupon bond maturing at time $T$ can be computed from equation (8) for every sample function of the short-term interest rate process.

Before concluding this section, it is useful to note here that parameters of the RS model need to be estimated for each currency in order to carry out the numerical simulation. Some limited work on this is reported in the paper by Ritchken and Sankarasubramanian (1995b). Following the arguments in Ritchken and Sankarasubramanian (1995b), let $r(0)$ be the initial spot rate and $\kappa_{0}, \sigma_{0}$ and $\gamma_{0}$ denote the parameters of a benchmark model. If $\kappa, \sigma$ and $\gamma$ are the parameters of an alternative model, then in order to ensure that the initial volatilities in the term structure are common across different models it is necessary to restrict the parameters of the alternative model so that the following relation holds:

$$
\sigma[r(0)]^{\gamma} e^{-\kappa T}=\sigma_{0}[r(0)]^{\gamma_{0}} e^{-\kappa_{0} T} \quad \forall T \geq 0
$$

For the choice $\gamma_{0}=0$, the scaling parameter $\sigma_{0}$ is the volatility of the spot rate which can be easily estimated from the historical data. By choosing $\kappa=\kappa_{0}$, all initial volatilities in the term structure can be made the same across different models if one sets $\sigma[r(0)]^{\gamma}=\sigma_{0}[r(0)]^{\gamma_{0}}$. Using historical forward rate yield curves, the parameter $\kappa$ can be estimated by computing the best least squares fit to the initial term structure of forward rate volatility. This estimation is carried out with the elasticity parameter set to $\gamma=0$ in equation (15). More details regarding this estimation is given in Section 6.1. 


\section{Evolution of exchange rates}

The modelling of the exchange rate process is probably one of the most extensively studied topics in international finance (see Frankel (1990)). Although various models have been proposed in the literature to describe the evolution of exchange rates, most of them have been reported to fail empirical tests that try to check for unbiasedness of the exchange rate forecast. In fact Meese and Rogoff (1983) show that in terms of forecasting power a simple random walk model dominates. In spite of this reported evidence, it needs to be stressed here that the intention of modelling exchange rates in the present study is not for purposes of superior forecasting efficiency. Rather, the study reported here requires a suitable model for computing the distribution of the currency returns at the end of the investment horizon in order to choose optimal portfolios. For such a purpose, the model chosen should ensure that under a risk neutral probability measure (see Pliska (1997)) the expected pay-off as measured in any base currency for holding risk-free bonds of different countries should be identical. This condition is necessary to exclude arbitrage opportunities, and hence, to ensure that an optimal solution to the asset allocation problem can be found. Note that when arbitrage opportunities exist, there will be no solution to the optimal portfolio selection problem (see Pliska (1997)). To ensure the no arbitrage condition, we begin with a simple model that assumes that uncovered interest rate parity holds over a short interval of time. This model is later refined to account for the empirical evidence suggesting that volatility of currency returns exhibit GARCH effects (see Heynen and Kat (1994)) without violating the above condition. This is done by including a Poisson process (see Feller (1971)) that models the jumps in the volatility of the returns that occur in practice. The details are discussed in Section 4.1.

For an investor holding a riskless bond of a particular country, the instantaneous rate of return received is equal to the short-term risk-free rate in that country. Under the assumption that there is no risk premium involved in holding foreign bonds, the uncovered interest rate parity condition requires that domestic and foreign bonds are perfect substitutes over a short period of time. Such a condition implies that the process for the evolution of the exchange rate in the risk neutral measure associated with the domestic currency can be described by the following stochastic differential equation (see Flesaker and Hughston (1997)):

$d S(t)=S(t)\left[r_{0}(t)-r_{f}(t)\right] d t+\sigma S(t) d w(t)$

In the above equation, $r_{0}(t)$ and $r_{f}(t)$ are the instantaneous risk-free rate of return for the base currency and the foreign currency, respectively, $S(t)$ is the exchange rate at time $t$ with respect to the base currency (i.e. $S$ units of the base currency are required to purchase one unit of foreign currency), $w(t)$ is a Wiener process and $\sigma$ is the volatility of the exchange rate returns. If the investor is assumed to hold more than one currency, the evolution of exchange rates needs to be modelled for every currency as in equation (28). However, empirical evidence suggests that currency returns are correlated and this correlation is relatively stable over time. If one takes into account the correlation 
between currency returns in the model, then the evolution of exchange rates with respect to the base currency can be described by the vector stochastic differential equation

$$
d S_{i}(t)=S_{i}(t)\left[r_{0}(t)-r_{i}(t)\right] d t+\sigma_{i} S_{i}(t) \sum_{j=1}^{M} \alpha_{i j} d w_{j}(t), \quad i=1,2, \cdots, M
$$

In the above equation, $S_{i}(t)$ denotes the exchange rate of the $i$ th currency at time $t$ and the matrix $\left[\alpha_{i j}\right]$ is the Cholesky decomposition (see Golub and Van Loan (1987)) of the correlation matrix $\left[\rho_{i j}\right]$ between the currency returns. It is important to note here that the short-term interest rates that drive the exchange rate processes in (29) are themselves stochastic processes. The evolution of these shortterm interest rate processes have been modelled in Section 2.

Although the exchange rate process modelled in equation (29) appears to be adequate for short-term horizons, the model is clearly inadequate over longer intervals of time. This is because the model described by (29) assumes that the volatility of currency returns is constant over time. However, empirical evidence strongly suggests that volatility of currency returns is time varying and includes periods of high and low volatility, both of which revert to the long term mean. In order to account for such periods of low and high volatility, we require a model to describe the evolution of the volatility process. A popular model to explain the time varying nature of the volatility of currency returns is the GARCH(1,1) model (see Heynen and Kat (1994)). In the following section, the description of the GARCH $(1,1)$ process and the changes needed in the exchange rate model (29) to incorporate this behaviour are described below.

\subsection{Incorporating GARCH}

This section briefly describes the $\operatorname{GARCH}(1,1)$ process and a model to simulate such a process. Let $r_{t}=\ln \left(S_{t} / S_{t-1}\right)$ be the currency return process which is assumed to follow a $\operatorname{GARCH}(1,1)$ process. In this case, the variance of the currency returns can be modelled as

$$
\begin{aligned}
& r_{t}=\mu+\sigma_{t} \xi_{t} \\
& \sigma_{t}^{2}=\beta_{0}+\beta_{1} \varepsilon_{t-1}^{2}+\beta_{2} \sigma_{t-1}^{2}
\end{aligned}
$$

In the above equations, $\mu$ is the mean return over a short interval of time (usually assumed to be zero for currencies), $\sigma_{t}$ is the volatility of returns, $\beta_{0}, \beta_{1}$ and $\beta_{2}$ are the GARCH parameters with $\beta_{1}+\beta_{2}<1$, and $\varepsilon_{t}=\sigma_{t} \xi_{t}$ with $\xi_{t} \sim N(0,1)$ and independent and identically distributed over time. For the $\operatorname{GARCH}(1,1)$ model the one-step forecast of the conditional variance is given by

$E_{t}\left(\sigma_{t+1}^{2}\right)=\beta_{0}+\left(\beta_{1}+\beta_{2}\right) \sigma_{t}^{2}$

Further, the long-term forecast of the conditional variance converges to the unconditional variance $\bar{\sigma}^{2}$ of the return series which satisfies the equality 
$\lim _{k \rightarrow \infty} E_{t}\left(\sigma_{t+k}^{2}\right)=\bar{\sigma}^{2}=\frac{\beta_{0}}{\left(1-\beta_{1}-\beta_{2}\right)}$

Setting $\phi=\left(\beta_{1}+\beta_{2}\right)$ we get from (32) the equality

$\beta_{0}=(1-\phi) \bar{\sigma}^{2}$

From equations (31) and (33) we obtain, after rearranging the terms,

$E_{t}\left(\sigma_{t+1}^{2}\right)=\bar{\sigma}^{2}+\phi\left(\sigma_{t}^{2}-\bar{\sigma}^{2}\right)$

The objective here is to find a suitable model that describes the evolution of the volatility process $\sigma(t)$ given that one has a good estimate of the long-term variance $\bar{\sigma}^{2}$. In order to capture the random jumps that occur in the volatility function, the increment of a Poisson process will be used. Such a volatility process undergoing random jumps can be described by the equation,

$\sigma(t+1)=\sigma(t)+\theta d q(t)$

In this equation, $q(t)$ is a Poisson process with arrival rate $v$, and $\theta$ is a random variable uniformly distributed in the interval $[0, b]$ where, $b$ is the size of the maximum volatility jump. The equation describing the evolution of the variance of currency returns that includes a jump process in order to model the GARCH effects is given below.

$\sigma^{2}(t+1)=\bar{\sigma}^{2}+\phi\left[(\sigma(t)+\theta d q(t))^{2}-\bar{\sigma}^{2}\right]$

When there are $N$ exchange rates to be considered, the evolution of the volatility of returns for each exchange rate will be assumed to be described by the equation

$\sigma_{i}^{2}(t+1)=\bar{\sigma}_{i}^{2}+\phi_{i}\left[\left(\sigma_{i}(t)+\theta_{i} d q(t)\right)^{2}-\bar{\sigma}_{i}^{2}\right], \quad 1,2, \cdots, N$

It is important to note here that the time of occurrence of the jumps to the volatilities are assumed to be simultaneous (there is only one Poisson process), but however, the size of the jumps described by the uniformly distributed random variable $\theta_{i}$ are assumed to be independent. This assumption is consistent with the empirical observation that increases in exchange rate volatilities are strongly correlated across different markets.

The evolution of the exchange rates after incorporating the above changes to the volatility of returns is given by

$d S_{i}(t)=S_{i}(t)\left[r_{0}(t)-r_{i}(t)\right] d t+\sigma_{i}(t) S_{i}(t) \sum_{j=1}^{N} \alpha_{i j} d w_{j}(t), \quad i=1,2, \cdots, N$

where the value of $\sigma_{i}(t)$ at any time $t$ is determined from equation (37). It will be assumed here that the Poisson process $q(t)$ is uncorrelated with any of the Wiener processes $w_{j}(t)$ in equation (38). This 
assumption will ensure that equations (29) and (38) have the same expectations under the risk neutral probability measure in domestic currency. In the section below, a numerical scheme to simulate the exchange rates over the interval $t \in(0, T]$ is discussed.

\subsection{Simulating exchange rates}

This section describes a numerical method to simulate the sample paths of the vector stochastic differential equation given by equation (38). In trying to apply a higher order convergence scheme such as Milshtein scheme, one is faced with the problem of dealing with multiple Wiener integrals which cannot be expressed easily in terms of the increments of the corresponding Wiener processes (see Kloeden and Platen (1992)). In order to avoid these difficulties the Euler scheme will be used for simulating the sample functions. In the multi-dimensional case the sample function of the $i$ th stochastic differential equation given by (38) can simulated using the following discretised equation:

$S_{i}(k+1)=S_{i}(k)+S_{i}(k)\left[r_{0}(k)-r_{i}(k)\right] h+\sigma_{i}(k) S_{i}(k) \sqrt{h} \sum_{j=1}^{N} \alpha_{i j} \xi_{j}(k), \quad i=1,2, \cdots, N$

In the above equation, $h$ is the step size and $\xi_{j}(k)$ are random variables drawn from a standardised normal distribution with $\xi_{i}(k)$ and $\xi_{j}(k)$ being independent if $i \neq j$. The update equation for the volatility process $\sigma_{i}(k)$ requires simulating the increments of a Poisson process with an arrival rate $v$. It can be easily shown that the increment of a Poisson process will be a string of impulses with the inter-arrival times (time between successive Poisson impulses) being exponentially distributed with parameter $v$. For an exponential distribution with parameter $v$, the probability of an event occurring over a short interval of time $h=\Delta t$ is equal to $v h$ with terms of order $o(h)$ being neglected. Since such a probability transition has the Markov property, the time of occurrence of the jumps can be easily simulated using single sample tests (see Srichander and Walker (1993)). The details are given below.

Let $\xi(k)$ be a sequence of independent random variables drawn from a standardised normal distribution. We denote the occurrence of a jump in the volatility function at time step $k$ if the condition $\xi(k)>\tau$ is true where, $\tau$ is a suitably chosen threshold. The choice of the threshold is $\tau$ is made to ensure that the probability of a jump occurring in a short interval of time $h$ is equal to $v h$. This is done by choosing $\tau$ to satisfy the following equality:

$\frac{1}{\sqrt{2 \pi}} \int_{\tau}^{\infty} e^{-0.5 x^{2}} d x=v h$

If $\varphi(k)$ denotes an indicator variable which takes the value one if a jump has occurred at time step $k$ and the value zero when no jump has occurred, then the update equation for the variance of currency returns is given by 
$\sigma_{i}^{2}(k+1)=\bar{\sigma}_{i}^{2}+\phi_{i}\left[\left(\sigma_{i}(k)+\theta_{i} \varphi(k)\right)^{2}-\bar{\sigma}_{i}^{2}\right], \quad 1,2, \cdots, N$

In the above equation $\theta_{i}$ is a uniformly distributed random variable in the interval $\left[0, b_{i}\right]$. We will now discuss the formulation of the optimisation problem for choosing a suitable portfolio of global fixed-income securities.

\section{Optimisation problem}

In the earlier sections of this paper, the formulation of suitable models for describing the evolution of exchange rates and zero coupon bond prices was presented and numerical schemes to simulate the sample functions of the processes were described. Using the numerical schemes suggested, one can carry out a Monte Carlo simulation to compute the distribution of bond and currency returns in the base currency at the end of a given investment horizon. The distribution of the returns computed by carrying out such a Monte Carlo simulation will be used in this section to select the portfolio weights for the global fixed-income securities. Since investors prefer to consider optimality in the context of portfolio selection as a trade-off between the risk and expected return, the optimisation problem formulated in this section will be restricted to reflect such a trade-off. In other words, the selection of the optimal portfolio will be based on a mean-variance optimisation problem. However, it is important to mention here that since the Monte Carlo simulation will enable one to compute all the moments of the return at the end of the investment horizon, the choice of the optimal portfolio can be based on any other utility function of the investor.

In general, investors holding risk-free bonds will have restrictions on the permissible duration of the bond portfolios they hold. Further, the bond portfolios being held will have to be constantly rebalanced with the passage of time in order to ensure that the target duration is maintained. This, and the reinvestment of coupons paid are the normal transactions that arise when holding bond portfolios. However, it will be assumed here that the bonds being held by the investor are zero coupon bonds so that the question of coupon reinvestment does not arise. It is further assumed that in order to maintain a given target duration $D_{i}$ in the bond position of the $i$ th currency, a barbell portfolio comprising of two zero coupon bonds are held. This position is rebalanced every $n$th day to ensure that the target duration is maintained. This is done by selling both the zero coupon bonds and buying new ones at the existing market prices. The details of this transaction are outlined below for the $i$ th currency.

Let the barbell portfolio be comprised of zero coupon bonds having duration $T_{1}$ and $T_{2}$ years so that the duration of this barbell portfolio at time $t$ satisfies the relation

$D_{i}=u_{i 1} T_{1}+u_{i 2} T_{2}$

$u_{i 1}+u_{i 2}=1$ 
In the above equation, $u_{i 1}$ and $u_{i 2}$ are the portfolio weights and the price at time $t$ of the zero coupon bonds are given by $P_{i}\left(t, T_{1}+t\right)$ and $P_{i}\left(t, T_{2}+t\right)$, respectively. After the elapse of $\tau$ years $(\tau=n / 365)$, these bonds are assumed to be sold at the market price and the proceeds used to buy zero coupon bonds having a duration of $T_{1}$ and $T_{2}$ years. The return arising from such a trading strategy is given by

$$
R_{i}(t+\tau)=u_{i 1} \frac{P_{i}\left(t+\tau, T_{1}+t\right)-P_{i}\left(t, T_{1}+t\right)}{P_{i}\left(t, T_{1}+t\right)}+u_{i 2} \frac{P_{i}\left(t+\tau, T_{2}+t\right)-P_{i}\left(t, T_{2}+t\right)}{P_{i}\left(t, T_{2}+t\right)}
$$

It is important to note here that the returns $R_{i}(t+\tau)$ are random variables and are expressed in the local currency. The above trades are carried out in the interval $t, t+\tau \in\left[0, T_{M}\right]$, where $T_{M}$ denotes the end of the investment horizon. If we assume that a total number of $M=T_{M} / \tau$ rebalancing trades are carried out during the investment horizon, then the return from the $k$ th trade can be computed using the following relation:

$$
\begin{aligned}
R_{i}(k \tau)= & u_{i 1} \frac{P_{i}\left(k \tau, T_{1}+(k-1) \tau\right)-P_{i}\left((k-1) \tau, T_{1}+(k-1) \tau\right)}{P_{i}\left((k-1) \tau, T_{1}+(k-1) \tau\right)} \\
& +u_{i 2} \frac{P_{i}\left(k \tau, T_{2}+(k-1) \tau\right)-P_{i}\left(k \tau, T_{2}+(k-1) \tau\right)}{P_{i}\left((k-1) \tau, T_{2}+(k-1) \tau\right)}, \quad k=1, \cdots, M
\end{aligned}
$$

At the end of the investment period the bond return obtained by investing one unit of the $i$ th currency in the bond market is given by

$$
R_{i}\left(T_{M}\right)=\prod_{k=1}^{M}\left(1+R_{i}(k \tau)\right)-1
$$

As pointed out earlier, the investment return given by the above equation is expressed in the local currency. Note that for every sample function of the interest rate process, the price $P_{i}(t, T)$ of the $i$ th country's zero coupon bond maturing at time $T$ can be computed from equation (8), and hence the return given by equation (44). Equation (45) denotes the total return in the local currency at the end of the investment period for one particular sample function of the interest rate process. To emphasise this point, we will denote the total return in equation (45) for the $j$ th sample function of the interest rate process (simulated using equation (25)) as $R_{i}^{j}\left(T_{M}\right)$.

Using the discretised equations of the exchange rate process given by equation (39), one can simulate the sample functions of the exchange rate for each currency. Let us denote the value of the exchange rate of the $i$ th currency at time $T_{M}$ generated by the $j$ th sample function as $S_{i}^{j}\left(T_{M}\right)$. Then the value of total return for the $j$ th sample function expressed in the base currency is given by

$$
R_{i}^{j}=\left[S_{i}^{j}\left(T_{M}\right)\left(1+R_{i}^{j}\left(T_{M}\right)\right) / S_{i}(0)\right]-1, \quad i=1,2, \cdots, N
$$


If the base currency is assumed to be denoted by the index $i=0$, then there is no loss of generality in including this index value in the above equation provided we set $S_{0}^{j}\left(T_{M}\right)=S_{0}(0), \forall j$. In this case, $R_{0}^{j}$ will denote the total return for the $j$ th sample function at the end of the investment horizon. This return is achieved by holding risk-free bonds denominated in the base currency having a duration of $D_{0}$ years.

By carrying out a Monte Carlo simulation, the distribution of the returns for each currency in the portfolio can be computed. In order to reduce the standard error of the estimates, the antithetic variable technique can be used (see Hull (1993)) when carrying out the Monte Carlo runs. It is useful to note here that if instead of using the Monte Carlo simulation the historical data is used to compute the moments of the expected return distribution (which is the case in most studies), then a rather heuristic decision is required in order to decide the length of the historical data to be considered. As a rule of thumb, a longer period of historical data is used for selecting portfolios that need to be optimal for longer time horizons. However, as most people who have dealt with this problem know, this decision is rather arbitrary and the choice of a different period for historical data leads to considerable changes in the portfolio weights. The Monte Carlo technique presented here takes into account this change in the investment horizon quite naturally by changing the time horizon at which the return distribution is computed.

As mentioned earlier in this section, the choice of the optimal portfolio for the asset allocation problem will be posed as a mean-variance optimisation problem. Within this framework the optimisation problem to be solved for computing the optimal portfolio is the following:

$\begin{gathered}\text { Minimise } \\ x\end{gathered} \sum_{i=0}^{N} \sum_{k=0}^{N} x_{i} x_{k} C_{i k}-\lambda \sum_{i=0}^{N} x_{i} \bar{R}_{i}$

subject to the condition

$\sum_{i=0}^{N} x_{i}=1, \quad x_{i} \geq 0, \quad i=0,1, \cdots, N$

Here,

$\bar{R}_{i}=\frac{1}{L} \sum_{j=1}^{L} R_{i}^{j} \quad$ and $\quad C_{i k}=\frac{1}{L-1} \sum_{j=1}^{L}\left(R_{i}^{j}-\bar{R}_{i}\right)\left(R_{k}^{j}-\bar{R}_{k}\right)$

If the base currency is to be excluded from the portfolio, then we start the summations in equations (47) and (48) from $i=1, k=1$ rather than from $i=0, k=0$. The parameter $\lambda$ in equation (47) denotes the trade-off between risk and return. Setting $\lambda=0$ in (47) will result in the minimum variance portfolio. In equation (49), $L$ denotes the number of Monte Carlo simulation runs. In the next section the optimal portfolios selected using the Monte Carlo simulation technique are presented. The out-ofsample performance of the portfolios are examined by computing the realised return and realised 
volatility over the investment period and plotting the location of the optimal portfolios on an efficient frontier graph. The realised return and volatility of the bond portfolios (in the base currency) are computed using historical zero coupon curves.

\section{Numerical results}

This section presents the numerical results for the global asset allocation problem formulated in the earlier section. In the example problem considered, the base currency was assumed to be the US dollar and the portfolio consisted of risk-free bonds from Germany, France, Japan, Switzerland, the United Kingdom and the United States. The investment horizon was assumed to be 2 years. In order to compute the optimal portfolios, a total number of 4,000 Monte Carlo simulations were performed. In the simulations, antithetic variables were used for variance reduction. The step size used in the simulation was $\Delta t=1 / 365$ which corresponds to a one day time interval. The entire coding of the numerical schemes for computing optimal portfolios was done in the $\mathrm{C}$ language. Note that since the simulation of the sample functions of the short-term interest rate process requires the differentiation of the continuously compounded forward rate curve, the zero coupon curves generated must be smooth (twice continuously differentiable). In the present study, smooth zero coupon curves were generated using basis splines (see Ramaswamy (1997)). The data used to generate the zero coupon and forward rate curves were inter-bank deposit rates up to one year and swap rates from 2 to 10 years. The Libor curve was used in the study because the BIS maintains a historical database of zero coupon and forward rate curves starting from January 1990 constructed using the deposit and swap rates. This data has been used in the present study to estimate the parameters of the interest rate model.

\subsection{Model parameters}

The estimation of the interest rate model parameters was carried out using daily historical zero coupon and forward rate curves starting from January 1990 until March 1997. The elasticity parameter $\gamma$ of the interest rate model was assumed to be 0.5 and was not part of the estimation procedure. The parameter $\kappa$ was estimated by minimising the least squares error between the observed volatility of the forward rate curves and the volatility of the benchmark model (corresponding to $\gamma=0$ ) given by equation (15) for the maturities $\frac{1}{4}, \frac{1}{2}, 1$, $2,3,4,5,7$ and 10 years. The estimation problem is posed as

$$
\underset{\kappa}{\operatorname{Min}} \sum_{i=1}^{n}\left(\hat{\sigma}_{f}\left(0, T_{i}\right)-\sigma_{f}\left(0, T_{i}\right)\right)^{2}
$$

In the above equation, $\sigma_{f}\left(0, T_{i}\right)$ is the observed volatility (using historical data) of the forward 
interest rates with maturity $T_{i}$ where, $T_{i} \in\left\{\frac{1}{4}, \frac{1}{2}, 1,2,3,4,5,7,10\right\}$ and $\hat{\sigma}_{f}\left(0, T_{i}\right)$ is the estimated volatility computed using equation (15) for particular choice of $\kappa$. This estimation is carried out under the choice $\gamma=0$. Table 1 shows the parameters of the interest rate model obtained using this optimisation procedure for different currencies. These model parameters were used in the simulations to compute optimal portfolios. In Table 1 , the nominal volatility $\sigma_{i}^{0}$ refers to the case when $\gamma=0$. The actual volatility parameter used in the simulations is a function of the prevailing short-term interest rate and is given by $\sigma_{i}=\sigma_{i}^{0} /\left[r_{i}(0)\right]^{\gamma_{i}}$.

Table 1

Interest rate model parameters

\begin{tabular}{lccc}
\hline Currency & $\kappa_{i}$ & $\gamma_{i}$ & $\sigma_{i}^{0}$ \\
\hline CHF & 0.219 & 0.50 & 0.0264 \\
DEM & 0.218 & 0.50 & 0.0231 \\
FRF & 0.162 & 0.50 & 0.0253 \\
GBP & 0.225 & 0.50 & 0.0336 \\
JPY & 0.163 & 0.50 & 0.0270 \\
USD & 0.090 & 0.50 & 0.0159 \\
& & & \\
\hline
\end{tabular}

The estimation of the correlation matrix and long-term volatility of the exchange rate models were carried out using weekly data of exchange rate returns over the period June 1993 to June 1997. The choice of the parameters for the jump process in the exchange rate volatility function was based on a rather ad hoc procedure. For instance, the number of volatility jumps per year was assumed to be 30 (which corresponds to the parameter $v$ ) and the maximum size of the volatility jumps was assumed to be $3 \%$ for the pound sterling and $4 \%$ for other currencies. This choice was based on estimating the average number of jumps per year and the maximum size of the jumps for all the currencies using exponentially weighted historical volatility of exchange rate returns (since such a model has volatility behaviour similar to that of the GARCH model). The rate of decay of the volatility shocks (given by $\phi=\beta_{1}+\beta_{2}$ ) is chosen based on the $\operatorname{GARCH}(1,1)$ model parameters reported in Heynen and Kat (1994). The issue of estimating the parameters of the jump model in a more systematic manner will be addressed in a separate study. The various model parameters used in the present study to simulate the sample paths of exchange rates are given in Table 2. 
Table 2

Exchange rate model parameters (Period: 9th June 1993 - 11th June 1997)

\begin{tabular}{|c|c|c|c|c|c|c|c|c|}
\hline \multirow[t]{2}{*}{ Currency } & \multicolumn{5}{|c|}{ Correlation matrix } & \multirow[t]{2}{*}{$\sigma_{i}$} & \multirow[t]{2}{*}{$\phi_{i}$} & \multirow[t]{2}{*}{$\theta_{i}$} \\
\hline & DEM & JPY & GBP & FRF & $\mathrm{CHF}$ & & & \\
\hline DEM & 1.000 & 0.549 & 0.696 & 0.946 & 0.933 & 0.0720 & 0.96 & 0.04 \\
\hline JPY & 0.549 & 1.000 & 0.274 & 0.509 & 0.538 & 0.0861 & 0.98 & 0.04 \\
\hline GBP & 0.696 & 0.274 & 1.000 & 0.709 & 0.654 & 0.0585 & 0.98 & 0.03 \\
\hline FRF & 0.946 & 0.509 & 0.709 & 1.000 & 0.911 & 0.0698 & 0.96 & 0.04 \\
\hline $\mathrm{CHF}$ & 0.933 & 0.538 & 0.654 & 0.911 & 1.000 & 0.0803 & 0.96 & 0.04 \\
\hline
\end{tabular}

\subsection{Optimal portfolios}

It has been assumed in the numerical study that the duration of the bond portfolios in individual countries is $3 \frac{1}{2}$ years, and this portfolio is comprised of 2 and 7-year zero coupon bonds. The bond portfolio is assumed to be rebalanced once every week. By carrying out the Monte Carlo simulation, the optimal portfolios for an investment horizon of 2 years (June 1997 to June 1999) were computed for different risk preferences. The results of the simulation study are shown in Table 3. In this table, the term "Mean return" denotes the annualised expected return at the end of the investment horizon in the domestic currency. It may be of interest to mention here that the portfolio weights selected by the optimisation scheme are well balanced without requiring additional constraints.

Table 3

Optimal portfolio composition (Period: 17th June 1997 to 16th June 1999)

\begin{tabular}{rrrrrrrr}
\hline$\lambda$ & \multicolumn{6}{c}{ Optimal portfolio weights (\%) } & Mean \\
\cline { 2 - 6 } & DEM & JPY & GBP & FRF & CHF & USD & return \\
\hline 0.0 & 1.34 & 0.54 & 0.84 & 0.72 & 0.41 & 96.16 & 6.40 \\
0.1 & 11.72 & 1.74 & 2.97 & 5.09 & 1.54 & 76.94 & 6.42 \\
0.4 & 10.32 & 5.19 & 5.28 & 11.76 & 1.32 & 66.14 & 6.42 \\
0.5 & 10.37 & 5.86 & 5.95 & 13.93 & 1.25 & 62.65 & 6.48 \\
1.0 & 15.49 & 12.04 & 10.78 & 27.29 & 2.12 & 32.27 & 6.51 \\
\hline
\end{tabular}




\subsection{Out-of-sample performance}

In this section, the out-of-sample performance of the portfolios selected by the Monte Carlo simulation technique is examined. This is then compared against the out-of-sample performance of the minimum variance portfolio and a portfolio that uses equal weights for all assets. The motivation for using equal weights comes from the study reported by Dumas and Jacquillat (1990) where mention is made that the choice of a neutral Bayesian prior will result in equal weights for all currencies in the portfolio. The out-of-sample performance of the portfolios is examined by comparing the realised return and the volatility of returns. The realised return is computed by rebalancing the barbell portfolio on a weekly basis. Using the weekly sample of realised returns for each security in the portfolio, an efficient frontier is plotted and performance of the various portfolios in terms of realised risk and return are compared. In the present study, two different historical periods were used to carry out this out-of-sample analysis. The first one comprised the period 10th January 1994 to 8th January 1996. This period was specifically chosen because the bond price volatilities were at historical highs and the US dollar weakened against most other currencies considered in the study. The other sample period considered in the study was 4th March 1996 to 3rd March 1997. Again the importance of this period is the strengthening of the US dollar against all major currencies except the pound sterling. For each case study, 4 years of weekly exchange rate returns were used to compute the correlation matrix and historical volatility for the exchange rate model. The parameters of the interest rate model were assumed to be the same as in the earlier study. Although such an assumption would tend to contribute to in-sample analysis, it was observed that the interest rate model parameters changed insignificantly when daily data of yield curves between the period January 1990 to January 1994 was used for estimation. For this reason, the interest rate model parameters were kept the same. The exchange rate model parameters used in the study are shown in Tables 4 and 5. The optimal portfolio composition for various risk preferences are shown in Tables 6 and 7. The annualised realised return (in the domestic currency) and volatility of returns based on the weekly sampling are also shown in the tables. The Sharpe ratio of the portfolios given in the tables refer to the ratio between the excess return (measured against the risk-free rate in the domestic currency) and the volatility of the returns.

There are several interesting observations to be made when one examines Tables 6 and 7 . For the investment period January 1994 to January 1996, the portfolios selected by the method proposed here have very good Sharpe ratios. This can be seen from the location of the portfolios on an efficient frontier graph shown in Figure 1. In this figure, the portfolio L4 refers to the optimal portfolio for the choice $\lambda=0.4$, the portfolio MIN refers to the minimum variance portfolio and the portfolio EQW refers to the one with equal weights assigned to all assets. The portfolios selected by the method described in this paper (indicated by the symbol o in the figure) can be seen to lie close to the efficient frontier. It can be seen from Figure 1 that the minimum variance portfolio underperforms all other portfolios during this period. On the other hand, the portfolio with equal weights has performed very well during this period. Figure 2 shows the efficient frontier and the location of the 
various portfolios for the investment period March 1996 to March 1997. During this period it can be seen from Figure 2 that the minimum variance portfolio has outperformed all other portfolios. The worst performing portfolio, however, is the portfolio with equal weights. On the other hand, the portfolio L4 (for the choice $\lambda=0.4$ ) performs reasonably well in terms of realised return to volatility of returns.

The results from the out-of-sample analysis are quite encouraging since the portfolios selected by the optimisation approach given here have performed quite well in terms of the Sharpe ratio during both time periods under consideration. This is not the case for the minimum variance and equal asset weights portfolios whose performances are markedly different across the two periods. It may be of interest to mention here that the performance of the tangent portfolios was unsatisfactory

Table 4

Exchange rate model parameters (Period: 10th January 1990 - 5th January 1994)

\begin{tabular}{|c|c|c|c|c|c|c|c|c|}
\hline \multirow[t]{2}{*}{ Currency } & \multicolumn{5}{|c|}{ Correlation matrix } & \multirow[t]{2}{*}{$\sigma_{i}$} & \multirow[t]{2}{*}{$\phi_{i}$} & \multirow[t]{2}{*}{$\theta_{i}$} \\
\hline & DEM & JPY & GBP & FRF & $\mathrm{CHF}$ & & & \\
\hline DEM & 1.000 & 0.474 & 0.785 & 0.978 & 0.920 & 0.0929 & 0.96 & 0.04 \\
\hline JPY & 0.474 & 1.000 & 0.384 & 0.446 & 0.449 & 0.0762 & 0.98 & 0.04 \\
\hline GBP & 0.785 & 0.384 & 1.000 & 0.799 & 0.744 & 0.0956 & 0.98 & 0.03 \\
\hline FRF & 0.979 & 0.446 & 0.799 & 1.000 & 0.912 & 0.0912 & 0.96 & 0.04 \\
\hline $\mathrm{CHF}$ & 0.920 & 0.449 & 0.744 & 0.912 & 1.000 & 0.1010 & 0.96 & 0.04 \\
\hline
\end{tabular}

Table 5

Exchange rate model parameters (Period: 26th February 1992 - 28th February 1996)

\begin{tabular}{|c|c|c|c|c|c|c|c|c|}
\hline \multirow[t]{2}{*}{ Currency } & \multicolumn{5}{|c|}{ Correlation matrix } & \multirow[t]{2}{*}{$\sigma_{i}$} & \multirow[t]{2}{*}{$\phi_{i}$} & \multirow[t]{2}{*}{$\theta_{i}$} \\
\hline & DEM & JPY & GBP & FRF & $\mathrm{CHF}$ & & & \\
\hline DEM & 1.000 & 0.569 & 0.696 & 0.957 & 0.939 & 0.0847 & 0.96 & 0.04 \\
\hline JPY & 0.569 & 1.000 & 0.276 & 0.523 & 0.551 & 0.0828 & 0.98 & 0.04 \\
\hline GBP & 0.696 & 0.276 & 1.000 & 0.714 & 0.654 & 0.0744 & 0.98 & 0.03 \\
\hline FRF & 0.957 & 0.523 & 0.714 & 1.000 & 0.915 & 0.0832 & 0.96 & 0.04 \\
\hline $\mathrm{CHF}$ & 0.939 & 0.551 & 0.654 & 0.915 & 1.000 & 0.0948 & 0.96 & 0.04 \\
\hline
\end{tabular}


Table 6

Optimal portfolio composition (Period: 10th January 1994 to 8th January 1996)

\begin{tabular}{|c|c|c|c|c|c|c|c|c|c|}
\hline \multirow[t]{2}{*}{$\lambda$} & \multicolumn{6}{|c|}{ Optimal portfolio weights (\%) } & \multirow{2}{*}{$\begin{array}{l}\text { Realised } \\
\text { return }\end{array}$} & \multirow{2}{*}{$\begin{array}{l}\text { Realised } \\
\text { volatility }\end{array}$} & \multirow{2}{*}{$\begin{array}{c}\text { Sharpe } \\
\text { ratio }\end{array}$} \\
\hline & DEM & JPY & GBP & FRF & $\mathrm{CHF}$ & USD & & & \\
\hline 0.0 & 10.72 & 0.29 & 2.37 & 2.55 & 1.27 & 82.80 & 7.91 & 3.99 & 0.91 \\
\hline 0.1 & 12.95 & 2.55 & 1.91 & 6.05 & 1.53 & 75.00 & 8.55 & 4.07 & 1.05 \\
\hline 0.4 & 15.87 & 7.00 & 2.92 & 12.24 & 1.50 & 60.48 & 9.57 & 4.43 & 1.19 \\
\hline 0.5 & 17.61 & 8.60 & 3.34 & 14.63 & 1.44 & 54.39 & 10.01 & 4.67 & 1.22 \\
\hline 1.0 & 28.47 & 17.13 & 5.56 & 26.86 & 2.05 & 19.93 & 12.64 & 6.58 & 1.27 \\
\hline
\end{tabular}

Table 7

Optimal portfolio composition (Period: 4th March 1996 to 3rd March 1997)

\begin{tabular}{|c|c|c|c|c|c|c|c|c|c|}
\hline \multirow[t]{2}{*}{$\lambda$} & \multicolumn{6}{|c|}{ Optimal portfolio weights (\%) } & \multirow{2}{*}{$\begin{array}{l}\text { Realised } \\
\text { return }\end{array}$} & \multirow{2}{*}{$\begin{array}{l}\text { Realised } \\
\text { volatility }\end{array}$} & \multirow{2}{*}{$\begin{array}{c}\text { Sharpe } \\
\text { ratio }\end{array}$} \\
\hline & DEM & JPY & GBP & FRF & $\mathrm{CHF}$ & USD & & & \\
\hline 0.0 & 1.54 & 0.14 & 0.49 & 0.54 & 0.21 & 97.07 & 4.17 & 4.00 & -0.28 \\
\hline 0.1 & 15.12 & 1.45 & 6.34 & 3.03 & 1.45 & 72.61 & 2.47 & 3.70 & -0.76 \\
\hline 0.2 & 17.35 & 2.02 & 10.92 & 3.89 & 1.29 & 64.53 & 2.52 & 3.70 & -0.75 \\
\hline 0.4 & 21.19 & 3.35 & 19.88 & 5.11 & 1.04 & 49.44 & 2.58 & 3.85 & -0.71 \\
\hline 1.0 & 34.12 & 6.31 & 49.21 & 5.35 & 1.67 & 3.34 & 3.40 & 5.30 & -0.36 \\
\hline
\end{tabular}

from the Sharpe ratio point of view during both time periods. The results from the numerical study are quite encouraging and tend to support the view that the method presented in this paper to a large extent avoids the estimation error problem which has plagued previous applications of the CAPM. Another interesting observation which can be made is that the models used in the study seem to be able to forecast excess returns well. For instance, the weight of UK Gilts in the portfolio for the investment period January 1994 to January 1996 is very low as given in Table 6. For the period March 1996 to March 1997, however, the weight of UK Gilts in the portfolio is considerably larger as can be seen from Table 7. Examining Figures 1 and 2, it can be seen that the UK Gilts (in US dollar terms) have actually outperformed all other assets during the period March 1996 to March 1997. 
Figure 1

Efficient frontier for investment period 10th January 1994 to 8th January 1996

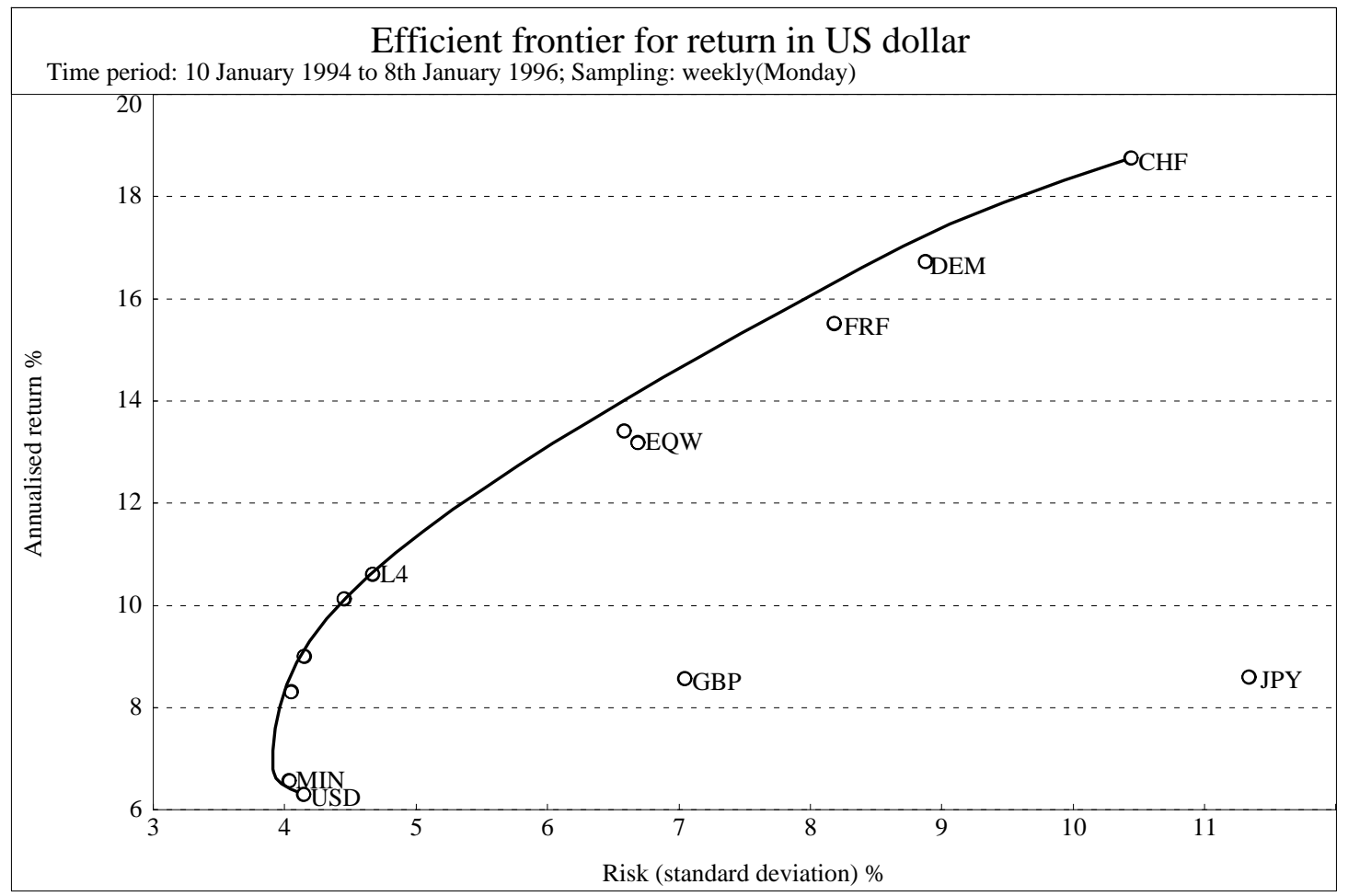

Figure 2

Efficient frontier for investment period 4th March 1996 to 4th March 1997

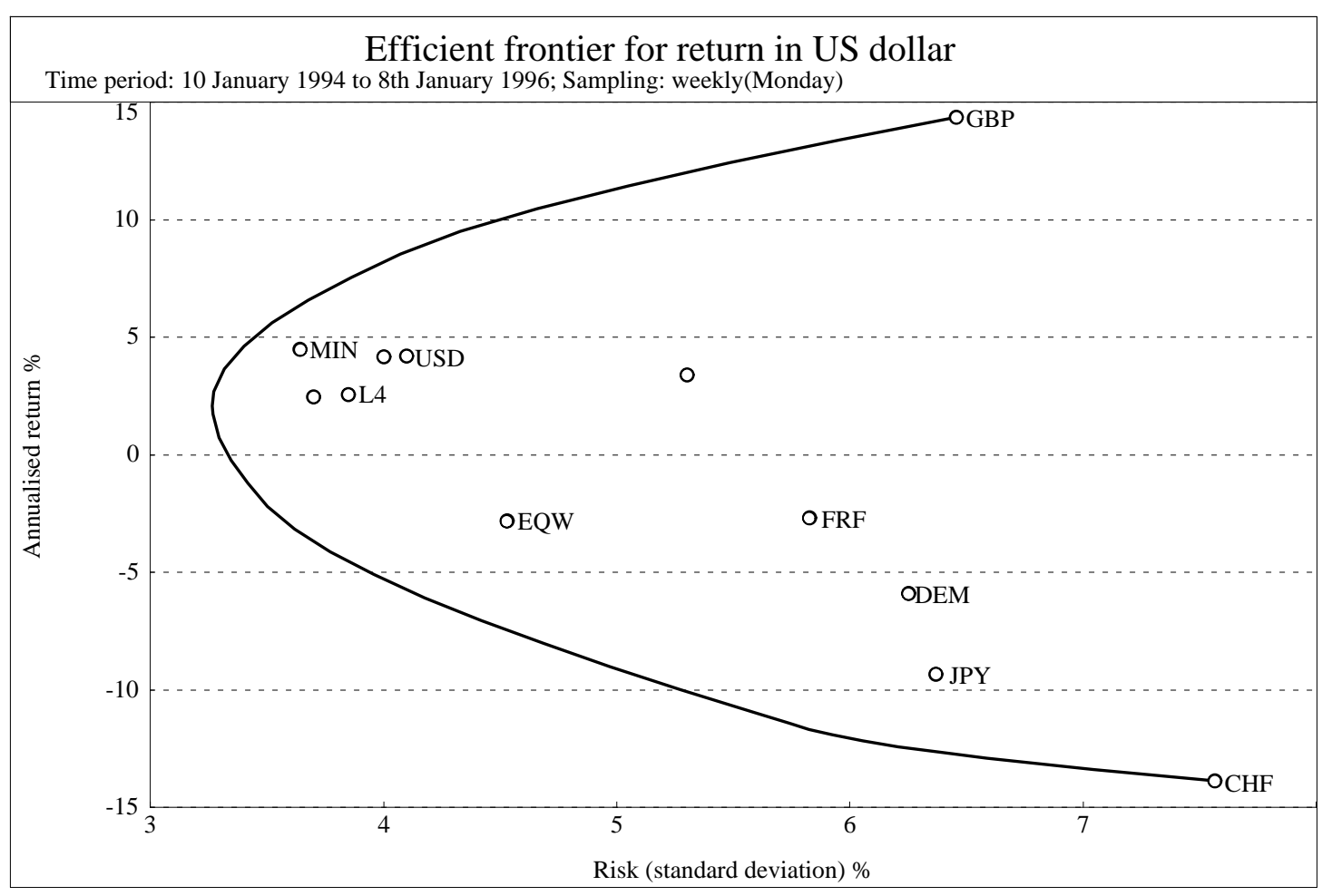


However, further work needs to be done to validate these observations on a wider class of assets and larger number of investment periods.

\section{Conclusions}

In this paper an approach was presented for global asset allocation in fixed-income securities which is new both in terms of modelling the evolution of exchange rate process and in terms of the method used to compute the distribution of expected returns at the end of the investment horizon. In particular, expected returns are extracted from the current term structure of interest rates and modelling its stochastic movements to drive both the evolution of discount bond prices and the exchange rate process so that the distribution of returns at the end of the investment horizon can be computed. Particular emphasis was given to incorporate empirically observed behaviour in the evolution of the exchange rate process by including a jump process in the volatility of exchange rate returns. The portfolios derived using the Monte Carlo simulation technique presented here lead to balanced portfolio weights without requiring additional constraints. It was shown by carrying out an out-of-sample performance analysis that the realised returns and Sharpe ratio of the portfolios were particularly good during different investment periods. This provides some evidence to the fact that the estimation error problem usually present in forecasting expected returns has been well addressed. However, there are a few additional modelling issues that need to be addressed before this asset allocation model can be extended to cover fixed-income securities in a more global framework. These issues are described below.

In selecting a suitable model to describe the evolution of exchange rates, the uncovered interest rate parity model was chosen because it ensures that risk-free bonds of different countries are perfect substitutes over a short period of time. However, investors holding foreign bonds may demand an additional risk premium during certain periods of time depending on the economic conditions prevailing in the foreign country. If this is the case, then the assumption that risk-free bonds of different countries are perfect substitutes may not be valid. In a mathematical sense, this would imply that the risk neutral process for the foreign risk-free rate $r_{f}$ will be different in the risk neutral world of the domestic investor and will be given by another process $r_{f}^{\prime}$. The exchange rate model used in the present study did not differentiate between these two processes. Although identifying the process $r_{f}^{\prime}$ will in general be difficult, the use of this in the exchange rate model may have the potential to further improve the out-of-sample performance of the portfolios selected using the method presented in this paper. However, this needs to be further investigated. As was mentioned earlier in this paper, the estimation of the parameters of the jump process in the exchange rate volatility needs to be done in a more systematic manner. Before concluding the paper, it may be useful to mention that the jump stochastic model introduced in this paper may prove to be useful in its own right to value long-term options on foreign exchange and could be a subject of independent study. 


\section{References}

Black, F., E. Derman and W. Toy (1990): "A One-Factor Model of Interest Rates and its Application to Treasury Bond Options", Financial Analysts Journal, Vol. 46, pp. 33-39.

Black, F. and R. Litterman (1992): "Global Portfolio Optimization", Financial Analysts Journal, pp. 28-43.

Bliss, R. and P. Ritchken (1996): "Empirical Tests of Two State-Variable Heath-JarrowMorton Models", Journal of Money, Credit and Banking, Vol. 28, pp. 452-481.

Cox, J., J. Ingersoll and S. Ross (1985): "A Theory of the Term Structure of Interest Rates", Econometrica, Vol. 53, pp. 385-407.

Dumas, B. and B. Jacquillat (1990): "Performance of Currency Portfolios Chosen by a Bayesian Technique: 1967-1985", Journal of Banking and Finance, Vol. 14, pp. 539-558.

Engle, R. and T. Bollerslev (1986): "Modelling the Persistence of Conditional variance", Econometric Reviews, Vol. 5, pp. 1-56. John Wiley.

Feller, W. (1971): "An Introduction to Probability Theory and its Applications: Vol. 1",

Flesaker, B. and L. Hughston (1997): "Positive Interest: Foreign Exchange", in Vasicek and Beyond, edited by L. Hughston, Risk Publications, pp. 351-367.

Frankel, J. (1990): "On Exchange Rates", MIT Press.

Golub, G. and C. Van Loan (1987): "Matrix Computations", John Hopkins University Press.

P. Hann (1995): "The Management of Canada's Foreign Exchange Reserves", M.S. Thesis, Faculty of Commerce and Business Administration, The University of British Columbia.

Heath, D., R. Jarrow and A. Morton (1992): "Bond Pricing and the Term Structure of Interest Rates: A New Methodology for Contingent Claims Valuation", Econometrica, Vol. 60, pp. $77-105$.

Heynen, R. and H. Kat (1994): "Volatility Prediction: A Comparison of the Stochastic Volatility, GARCH(1,1) and EGARCH(1,1) Models", Journal of Derivatives, pp. 50-65.

Heynen, R., A. Kemna and T. Vorst (1994): "Analysis of the Term Structure of Implied Volatilities", Journal of Financial and Quantitative Analysis, Vol. 29, pp. 31-56.

Hull, J. (1993): "Options, Futures, and Other Derivative Securities", Prentice Hall.

Hull, J. and A. White (1994): "Numerical Procedures for Implementing Term Structure Models I: Single-Factor Models", Journal of Derivatives, pp. 7-16.

Jorion, P. (1985): "International Portfolio Diversification with Estimation Risk", Journal of Business, Vol. 58, pp. 259-278.

King, A. (1993): "Asymmetric Risk Measures in Tracking models for Portfolio Optimization Under Uncertainty", Annals of Operations Research, Vol. 45, pp. 165-177. 
Kloeden, P. and E. Platen (1992): "Numerical Solution of Stochastic Differential Equations", Vol. 23, Springer Verlag.

Lederman, J. and R. Klein (1994): "Global Asset Allocation: Techniques for Optimizing Portfolio Management", John Wiley.

Markowitz, H., P. Todd, G. Xu and Y. Yamane (1993): "Computation of MeanSemivariance Efficient Sets by the Critical Line Algorithm", Annals of Operations Research, Vol. 45, pp. 307-317.

Meese, R. and K. Rogoff (1983): "Empirical Exchange Rate Models of the Seventies: Do They Fit Out of Sample?", Journal of International Economics, Vol. 14, 1983, pp. 3-24.

Milshtein, G.N. (1974): "A Method of Second-Order Accuracy Integration of Stochastic Differential Equations", Theory of Probability and Applications, Vol. 19, pp. 396-400.

Pliska, S. (1997): "Introduction to Mathematical Finance: Discrete Time Models", Blackwell Publishers.

Ramaswamy, S. (1997): "Estimation of the Zero Coupon Yield Curve", BIS internal document.

Ritchken, P. and L. Sankarasubramanian (1995a): "Volatility Structure of Forward Rates and the Dynamics of the Term Structure", Mathematical Finance, Vol. 5, pp. 55-72.

Ritchken, P. and L. Sankarasubramanian (1995b): "The Importance of Forward Rate Volatility Structures in Pricing Interest Rate Sensitive Claims", Journal of Derivatives, pp. 25-41.

Rogers, L.C. (1993): "Which Model for Term-Structure of Interest Rates Should One Use?", Mathematical Finance, Vol. 65, Springer Verlag, pp. 93-115.

Srichander, R. and B. Walker (1993): "Stochastic Stability Analysis for Continuous Time Fault Tolerant Control Systems", International Journal of Control, 57, pp. 433-452.

Vasicek, O. (1977): "An Equilibrium Characterization of Term Structure", Journal of Financial Economics, Vol. 5, pp. 177-188.

Xu, X. and S. Taylor (1994): "The Term Structure of Volatility Implied by Foreign Exchange Options", Journal of Financial and Quantitative Analysis, Vol. 29, pp. 57-74. 




\section{Recent BIS Working Papers}

30

November 1995

31

December 1995

32

December 1995

33

January 1996

34

January 1996

35

July 1996

36

August 1996

37

September 1996

38

October 1996

39

January 1997

40

March 1997

41

May 1997

42

June 1997

43

July 1997

44

July 1997

45

August 1997
Money demand stability and currency substitution in six

European countries (1980-1992)

Testing the quantity theory using long-run averaged

cross-country data

The anatomy of the bond market turbulence of 1994

Derivatives and asset price volatility: a test using

variance ratios

Monetary policy and the behaviour of interest rates: are long rates excessively volatile?

Varieties of monetary policy operating procedures: balancing monetary objectives with market efficiency

Estimation of speculative attack models: Mexico yet again

Does the term structure predict recessions?

The international evidence

International agreements in the area of banking and finance: accomplishments and outstanding issues

Banking system failures in developing and transition countries: diagnosis and prediction

Monetary policy operating procedures industrial countries

The euro and European financial markets

Measuring monetary policy shocks in France, Germany and Italy: the role of the exchange rate

Exchange rate regimes and the expectations hypothesis of the term structure

Is there excess comovement of bond yields between countries?

A multi-country comparison of the linkages between inflation and exchange rate competitiveness
Renato Filosa

Stefan Gerlach

Claudio E.V. Borio

Robert N. McCauley

Benjamin H. Cohen

Stefan Gerlach

Joseph Bisignano

William R. Melick

Henri Bernard and Stefan Gerlach

William R. White

Patrick Honohan

Claudio E. V. Borio

Robert N. McCauley and William R. White

Frank Smets

Stefan Gerlach and Frank Smets

Gregory D. Sutton

Steven B. Kamin 